\title{
Benign Mediastinal/Hiler Lenfadenopatilerde Etyoloji ${ }^{*}$
}

\section{Müge ERBAY ${ }^{1}$, Tevfik ÖZLÜ ${ }^{2}$, Yılmaz BÜLBÜL ${ }^{2}$, Funda ÖZTUNA ${ }^{2}$, Savaş ÖZSU $^{3}$, Celal TEKİNBAŞ ${ }^{4}$}

1 Bursa Uludağ Üniversitesi Tıp Fakültesi, Göğüs Hastalıkları Anabilim Dalı, Bursa.

2 Karadeniz Teknik Üniversitesi Tıp Fakültesi, Göğüs Hastalıkları Anabilim Dalı, Trabzon.

3 Çakmak Erdem Hastanesi, Göğüs Hastalıkları Kliniği, İstanbul.

4 Karadeniz Teknik Üniversitesi Tıp Fakültesi, Göğüs Cerrahisi Anabilim Dalı, Trabzon.

\section{ÖZET}

Çalışmamızda benign mediastinal/hiler lenfadenopati saptanan hastalar takip edilerek lenfadenopatiye neden olan hastalıkların dağılımı incelenmiştir. Çalışmamız, Mayıs 2015 ile Haziran 2016 tarihleri arasında prospektif olarak yürütüldü. Çalışmaya mediastinal/hiler lenfadenopati nedeni ile EBUS/ Mediastinoskopi/ Torakoskopi yapılan olgular alındı ve başlangıçta biyopside malignite saptanan hastalar çalıșmadan çıkarıldı. Çalışmaya dahil edilen benign mediastinal/hiler LAP saptanan 93 hastanın \%59.1 (55)'i kadın, \%40.9 (38)'u erkek, yaş ortalaması $55.1( \pm 12.6)$ idi. Seksen üç hastaya Endobronşiyal Ultrason Eşliğinde Transbronşiyal İğne Aspirasyonu (EBUS TBİA), 7 hastaya mediastinoskopi, 2 hastaya Video-asiste torakoskopik cerrahi (VATS) ve 1 hastaya torakotomi yapıldı. Hastaların \%53.8 (50)'inde sarkoidoz, \%12.9 (12)'unda antrakoz, \%5.1 (5)'inde tüberküloz, \%4.3 (4)'ünde silikozis, \%1.1 (1)'inde churg strauss sendromu, \%1.1 (1)'inde hipersensitivite pnömonisi, \%1.1 (1)'inde enfeksiyon, \%1.1 (1)'inde kanser, \%19.4 (18)'ünde nedeni bilinmeyen lenfadenopati bulundu. Çalışmamızdaki esas bulgu benign mediastinal/hiler lenfadenopatinin en yaygın nedeninin sarkoidoz olarak bulunmasıdır. Enfeksiyöz nedenlerden tüberküloz ise 3. sıklıkta LAP nedeni olarak bulunmuştur. Ayrıca granülomatöz lenfadenitin benign mediastinal/hiler lenfadenopatilerin yarısından fazlasını oluşturduğu görülmüştür. Mediastinel/hiler LAP'lerin büyük oranda EBUS TBİA yöntemiyle örneklenebildiği saptanmıştır. Ayırıcı tanının yapılamadığı olgularda takip ile tanıya gidilebileceği de anlaşılmaktadır.

Anahtar Kelimeler: Benign lenfadenit. Sarkoidoz. Granülomatöz lenfadenit.

Etiology of Benign Mediastinal/Hilar Lymphadenopathy

\section{ABSTRACT}

Our study was conducted as prospectively between May 2015 and June 2016. Cases that underwent EBUS/ Mediastinoscopy / Thoracoscopy with the diagnosis of mediastinal/hilar lymphadenopathy were included in the study and patients who were diagnosed to have malignancy in the initial biopsy were excluded from the study. The included 93 cases consisted of $40.9 \%$ men (38) and $59.1 \%$ women (55) with a median age of $55.1( \pm 12.6)$ years. Patients underwent Endobronchial Ultrasound Guided Transbronchial Needle Aspiration (EBUS TBNA) (83 patients), mediastinoscopy (7 patients), video-assisted thoracic surgery (2 patients) and thoracotomy (1 patient). The final diagnosis of the patients was accepted to be sarcoidosis in 50 (53.8\%), anthracosis in 12 (12.9\%), tuberculosis in $5(5.1 \%)$, silicosis in 4 (4.3\%), churg strauss syndrome in $1(1.1 \%)$, hypersensitivity pneumonia in $1(1.1 \%)$, infectious in $1(1.1 \%)$, malignancy in $1(1.1 \%)$ and uncertain in $18(19.4 \%)$. The main findings of this study revealed that sarcoidosis was the most common cause for benign mediastinal/hilar lymphadenopathy. Tuberculosis was the third most common cause of benign mediastinal/hilar LAP. Furthermore, granulomatous lymphadenitis comprised more than half of benign mediastinal / hilar lymphadenopathy. It has been found that mediastinal/hilar LAP can be sampled by EBUS TBNA method to a large extent. In cases with impossible differential diagnosis, follow-up of patients may direct one to diagnosis in time.

Key Words: Benign lymphadenitis. Sarcoidosis. Granulomatous lymphadenitis.

Geliş Tarihi: 21 Temmuz 2019

Kabul Tarihi: 11 Kasım 2019

* Ulusal Akciğer Sağlığı Kongresi'nde poster bildiri olarak sunulmuştur (14-18 Mart 2018, Antalya).

Dr. Müge ERBAY

Bursa Uludağ Üniversitesi Tıp Fakültesi,

Göğüs Hastalıkları Anabilim Dalı,

İmmunoloji ve Alerji Bilim Dalı,

Bursa.

Tel.: 05365754205

E-posta: drmugerbay@gmail.com
Mediastinal/hiler lenf nodları, lokalize enflamatuvar hastalıklar veya primer lenfatik tümörler yanında; toraksın içinden, göğüs duvarından, memeden veya uzak bir organdan etkilenebilmektedir. Bu nedenle mediastinal/hiler lenfadenopati (LAP) oluşumundan geniş bir hastalık grubu sorumludur. En sık neden olan hastalıklar arasında lenfoma, metastatik karsinom, sarkoidoz ve tüberküloz yer almaktadır ${ }^{1}$. Mediastinal benign lenf nodlarının en sık sebebi ise granülomatoz hastalıklardir ${ }^{2}$. 
Mediastinal lenfadenopatili hastalarda uygun tedavi yöntemini belirlemek için öncelikle histopatolojik tanıya ihtiyaç vardır. İnvazif yöntemle benign/malign LAP ayrımı histopatolojik olarak yapılabilmektedir. Fakat benign lenfadenopatiye neden olan hastalıkların ayırıc1 tanısı bu kadar kolay olmamaktadır. Benign LAP etyolojisinin çoğunluğunu oluşturan granülomatöz hastalıkların histopatolojisinin benzer özellikler taşıması, bu zorluğun en önemli nedenidir. Bundan dolayı, ayırıcı tanıda çok yönlü yaklaşım gerekli olmaktadır. Ayırıcı tanının zor olduğu bu durumla klinikte sık karşılaşılmakta ve tedavi yaklaşımı nedeni ile ayırıcı tanı önem taşımaktadır.

Çalışmamızda benign mediastinal/hiler LAP saptanan hastaların klinik, histopatolojik, seyir ve prognozuyla ilgili verileri değerlendirildi ve bulgularımızın benign mediastinal/hiler LAP etyolojisinde yol gösterici olmasını amaçladık.

\section{Gereç ve Yöntem}

\section{Çalışma Dizaynı}

Bu çalışma Mayıs 2015 ile Haziran 2016 tarihleri arasında prospektif gözlemsel olarak yürütüldü. Karadeniz Teknik Üniversitesi Etik Kurul onayı alındı.

\section{Olgular}

Mayıs 2015 ile Haziran 2016 tarihleri arasında hastanemize başvuran ve kısa çap1 $1 \mathrm{~cm}$ 'den büyük mediastinal lenfadenopati nedeni ile Endobronşiyal Ultrason (EBUS)/ Mediastinoskopi/ Torakoskopi gibi en az bir invazif işlem uygulanmış olan olgular alındı.

Çalışmaya dahil edilen hastaların öyküsü (şikayetler, ilaçlar, maruziyet ve sigara öyküsü), laboratuvar parametreleri (ACE, ARB), solunum fonksiyon testleri, tüberkülin deri testleri, radyolojik bulguları, uygulanan invazif işlem (EBUS, mediastinoskopi, torakoskopi) ve patoloji sonuçları kaydedildi.

\section{Tanımlamalar}

Sitopatolojik örnekler gruplara ayrılarak; (i) granülomatöz lenfadenit, olgun lenfositler ile nekroz içeren veya içermeyen granülom görülmesi, (ii) antrakoz, antrakotik cisimlerin görülmesi, (iii) reaktif hiperplazi, malign hücre veya granülom görülmeden olgun lenfositlerin görülmesi, (iiii) sınıflandırlamayan, lenfositlerin görülmediği yetersiz örnek olarak tanımlandı.

Uyumlu histolojik, radyolojik ve klinik bulgularla birlikte kültür negatifliği olduğunda sarkoidoz olarak tanımlandı. Kültür pozitifliği, dokuda mikroorganizma görülmesi, tutarlı klinikopatolojik durumda pozitif antijen/antikor saptanması durumunda enfeksiyöz olarak tanımland $1^{3}$. Uygun mesleki anamnez ve maruziyet öyküsü olan, uyumlu radyolojik değişiklik ve bu radyolojik görüntüye yol açacak enfeksiyöz, kanser, kollajenözler başta olmak üzere enflamatuvar nedenlerin dışlandığı hastalar pnömokonyoz olarak kabul edildi. Klinik ve radyolojik olarak uyumlu olup biyopside antrakoz tespit edilen kültür negatif hastalar antrakozis olarak tanımlandı. Bronşiyal astım, tam kan sayımında eozinofil oranının $\% 10$ veya üzerinde olmas1, multipl mononöropati veya polinöropati, akciğer grafisinde pulmoner infiltratların görülmesi, paranazal sinüs patolojisi ve biyopsi ile damar cidarı dışında eozinofilinin gösterilmesi kriterlerinden 4 veya daha fazlasına sahip olan hastalara Churg-Strauss Sendromu (CSS) tanısı konuldu ${ }^{4}$. Bu kriterlerle uyumlu olmayan hastalar, eşlik eden bir malignite olmaması, lenfadenopatiye neden olduğu bilinen ilaç kullanımı olmaması halinde nedeni bilinmeyen olarak kabul edildi. Normal serum anjiotensin dönüştürücü enzim (ACE) düzeyi 0-52 U/L’ydi.

\section{Çalıșma Protokolü}

Hastalar 3-6 ay kontrolleri ile takip edildi. Tedavisiz takip edilen, tedavi altında olan veya tedavisi tamamlanmış hastalar klinik, laboratuvar parametreleri (sedimentasyon, kalsiyum, C-Reaktif Protein), solunum fonksiyon testleri, akciğer radyografileri ve bazı olgular toraks bilgisayarlı tomografi ile izlendi.

Lenf nodunun ilk örneklenmesi sonrası mevcut veriler (klinik/ radyolojik/ laboratuvar/ histopatolojik) ile hastalara "ilk tanıları" konuldu. Sonrasında hastaların takipleri ve bazılarının ikinci kez lenf nodu örneklenmesi sonucunda "son tanı" belirlendi.

Hastaların takibinde; klinik ve radyolojik iyileşme "regresyon", klinik iyileşme mevcut fakat radyoloji benzer ise "stabil", semptom ve radyolojik kötüleşme mevcut ise "progresyon" olarak yorumland1.

\section{İstatistiksel Analiz}

Veriler bilgisayar ortamında SPSS 23 yazılım programı kullanılarak değerlendirildi. Verilerin dağılımı için Kolmogorov-Smirnov analizi yapıldı. İstatistiksel yöntemde parametrik değişkenler için Ki-Kare ve Student-t testi, nonparametrik değişkenler için MannWhitney U ve Kruskal Wallis analizi kullanıldı. İstatistiksel olarak anlamlı değer $\mathrm{p}<0.05$ olarak kabul edildi.

\section{Bulgular}

Mayıs 2015- Haziran 2016 tarihleri arasında mediastinal/hiler lenfadenopatisi saptanan 221 hastaya invazif örnekleme yapıldı ve 96'sı ilk biyopside malignite saptanması nedeniyle çalışmadan çıkarıldı. Kuşkulu kanser olan veya çalışmaya katılmayı kabul etmeyen 26 hasta çalışma dışı bırakıldı. Biyopsi sonucu yetersiz örnek (lenfosit izlenmeyen) olarak raporlanan 13 hastanın 6's1, ikinci biyopsi işlemi veya takibi olmaması nedeni ile çalışmadan çıkarıldı. 


\section{Benign Mediastinal/Hiler Lenfadenopatiler}

Benign mediastinal/hiler LAP saptanan 93 hasta çalışmaya dahil edildi. Hastaların \%59.1'i kadın, \%40.9'u erkek ve yaş ortalaması $55.1( \pm 12.6)$ idi. Hastaların \%68.8'i hiç sigara içmemişti. Başvuru yakınmalarına bakıldığında hastaların $55^{\prime}$ inde (\%59.1) öksürük, 49'unda (\%52.7) nefes darlığı, 26'sında (\%28) eklem ağrısı, 23'ünde (\%24.7) balgam, 19'unda (\%20.4) kilo kayb1, 18 'inde (\%19.4) göğüs ağrıs1, 13 'ünde $(\% 14)$ ateş, 10 'unda $(\% 10.8)$ gece terlemesi, 7’sinde (\%7.5) kan tükürme mevcuttu.

Tüberkülin deri testi (TDT) 45 hastaya yapılmış olup 30’unda (\%66.7) negatif saptandı. Serum ACE düzeyi ortalama $66.2 \pm 36.7 \mathrm{U} / \mathrm{L}$ olarak bulundu. Solunum fonksiyon testinde ortalama FEV1/FVC \%81.3 \pm 9.7 , FEV1 \%103.8 \pm 22.6 , FEV1 2.51 \pm 0.8 litre, FVC \%100.3 $\pm 23.8, \quad$ FVC $3.15 \pm 1.02 \quad$ litre, DLCO \%106.9 \pm 78.04 idi.

Şekil 1'de mediastinal/hiler LAP örneklemesinde kullanılan ilk invazif tanı yöntemleri ve histopatolojik sonuçları görülmektedir. İlk invazif tanı yöntemi olarak EBUS TBİA uygulanmış olup tanı konulamayan, klinik olarak alternatif tanıların düşünüldüğü, kanserin dışlanamadığı 18 hastaya hemen ikinci invazif işlem uyguland1. EBUS TBİA sonucunda; sitopatolojisi sinıflandırlamayan grupta olan 7 hastanın 3'üne mediastinoskopi, granülomatöz lenfadenit tespit edilen 5 hastaya mediastinoskopi ve 1 hastaya VATS, antrakoz olan 9 hastanın birine VATS ve yedisine mediastinoskopi, reaktif hiperplazi olan 1 hastaya mediastinoskopi yapıldı (Şekil 2). EBUS TBİA sonucu antrakoz olan bir hastanın ise takibinde akciğer grafisinde progresyon görülmesi üzerine tekrar EBUS TBİA yapıldı ve skuamöz hücreli karsinom saptandı. Sonuç olarak ikinci bir tanısal işlem ile tekrar biyopsi alınan 19 hastanın ilk biyopsi ile ikinci biyopsi sonucu arasında tutarlılık olduğu bulundu (к: 0.296, standart hata: 0.120, $\mathrm{p}=0.026$ ).

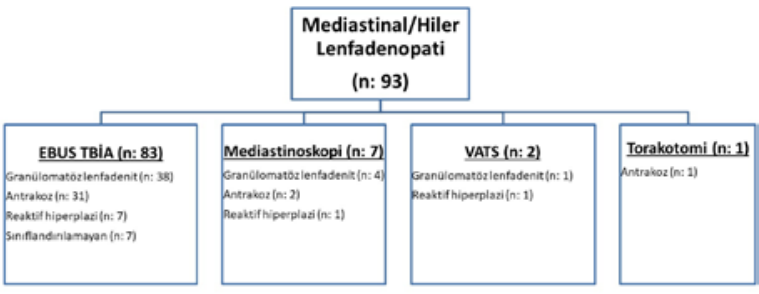

Sekil 1:

Mediastinal/Hiler Lenfadenopatilerin İlk İnvazif Tanı Yöntemleri ve Histopatolojik Sonuçları. EBUS TBİA: Endobronşiyal Ultrason Eşliğinde Transbronşiyal İ̆ne Aspirasyonu; VATS: Video-asiste torakoskopik cerrahi.

İkinci biyopsi sonuçları ile hastaların \%52.7 (49)'si granülomatöz lenfadenit, \%32.3 (30)’ü antrakoz, \%9.7 (9)'si reaktif hiperplazi, \%4.3 (4)'ü sınıflandırılamayan, \%1.1 (1)’i skuamöz hücreli karsinom olarak saptand1. Granülomatöz lenfadenit saptanan 49 hasta- nın 45'i (\%91.8) sarkoidoz, 2'si (\%4.1) tüberküloz, 1'i (\%2) silikozis, 1'i (\%2) nedeni bilinmeyen olarak kabul edildi.



Şekil 2:

EBUS TBİA Yapılan Hastalara İkinci Kez Uygulanan Invazif Tanı Yöntemleri ve Histopatolojik Sonuçları.

EBUS TBİA: Endobronşiyal Ultrason Eşliğinde

Transbronşiyal İğne Aspirasyonu; VATS: Video-asiste torakoskopik cerrahi.

Hastaların ilk biyopsiden sonra klinik, radyolojik ve histopatolojik açıdan değerlendirilmesi sonucunda; \%54.8 (51)'i sarkoidoz, \%19.4 (18)'ü antrakoz, \%5.4 (5)'ü tüberküloz, \%5.4 (5)'ü silikozis, \%2.2 (2)'si enfeksiyöz, \%1.1 (1)'i churg strauss sendromu, \%11.8 (11)'i nedeni bilinmeyen lenfadenopati olarak kabul edildi. Ancak takip sırasında hastaların 17'sinde tanıda değişiklik yapıldı. Dört hastada ikinci kez yapılan biyopsi sonucu ile tanı değişirken (Tablo I) diğer 13 hastada yeni ortaya çıkan klinik, laboratuvar, radyolojik bulgular sonrasında tanıda değişiklik yapıldı ve hastaların nihai tanıları belirlendi (Tablo II). Tüberküloz tanısı ile 6 ay antitüberküloz tedavisi verilen bir hastanın kontrol toraks bilgisayarlı tomografisi'nde (BT) lenf nodlarında değişiklik olmaması ve anlamlı kilo kaybı olması üzerine lenfoma şüphesi ile hastaya mediastinoskopi yapıldı ve granülomatöz lenfadenit saptanan, TB kültür negatif olan, göz tutulumu gelişen hastaya sarkoidoz tanısı konuldu. Maruziyet öyküsü olup lenf nodu biyopsisinde TB kültür negatif olan bir hasta başlangıçta silikozis olarak değerlendirilmişti ancak takipte bakılan balgam kültüründe Mycobacterium tuberculosis saptanması üzerine TB tanisı aldi.

Tablo I. İkinci Kez Biyopsi Yapılan ve Tanısı Değişen Hastaların İlk ve Son Tanıları

\begin{tabular}{lll}
\hline & \multicolumn{1}{c}{ İlk Tanı } & \multicolumn{1}{c}{ Son Tanı } \\
\hline $\mathbf{1}$ & Sarkoidoz & Skuamöz hücreli karsinom \\
$\mathbf{2}$ & Tüberküloz & Sarkoidoz \\
$\mathbf{3}$ & Nedeni bilinmeyen & Antrakozis \\
$\mathbf{4}$ & Nedeni bilinmeyen & Sarkoidoz \\
\hline
\end{tabular}


Tablo II. Mediastinal/Hiler Lenfadenopatili Hastaların Takip/Tekrar Biyopsi Sonrası Nihai Tanilar1

\begin{tabular}{lc}
\hline & Hasta sayısı (\%) \\
\hline Sarkoidoz & $50(53.8)$ \\
Antrakozis & $12(12.9)$ \\
Tüberküloz & $5(5.1)$ \\
Silikozis & $4(4.3)$ \\
Churg Strauss sendromu & $1(1.1)$ \\
Hipersensitivite Pnömonisi & $1(1.1)$ \\
Enfeksiyon & $1(1.1)$ \\
Kanser & $1(1.1)$ \\
Nedeni bilinmeyen & $18(19.4)$ \\
\hline
\end{tabular}

Toplam 47 hasta ortalama $6.4 \pm 3.1$ ay takip edildi. Hastaların 29'u (\%61.7) klinik, laboratuvar parametreleri, akciğer grafisi ve solunum fonksiyonları ile takip edilirken 18'i (\%38.3) toraks BT ile takip edildi. Takip edilen hastaların \%83 (39)'ü stabil, \%14.9 (7)'u regresyon, \%2.1 (1)'i progresyon olarak değerlendirildi.

\section{Tartışma}

Patolojik boyutta mediastinal LAP ile karşılaşma sıklığı ve bu LAP'ların nedenleri coğrafi alana, popülasyona, yaşam şekline ve sosyo-kültürel değişkenlere göre farklı olacaktır. Çalışmanın gerçekleştirildiği süre içinde merkezimize başvuran yaklaşık 15 bin hastadan 221'ine mediastinal lenfadenopati nedeniyle örnekleme yapılmıştır. Bu hastalardan 93'ünde tanı benign mediastinal/hiler lenfadenopati olarak konulmuştur. Bu durum, bulunduğumuz koşullarda mediastinal/hiler lenfadenopati nedeni olarak malignite yanında önemli oranda benign patolojilerin de düşünülmesi gerektiğini ortaya koymuştur.

Çalışmamızdaki mediastinal/hiler LAP'lı hastaların takipleri sonucunda nihai tanıları sirasıyla \%53.8 sarkoidoz, \%19.4 nedeni bilinmeyen, \%12.9 antrakoz, \%5.1 tüberküloz, \%4.3 silikozis, \%1.1 churg strauss sendromu, \%1.1 hipersensitivite pnömonisi, \%1.1 enfeksiyon ve \%1.1 kanser olarak bulunmuştur. Navani ve ark. larının çalışmasında, izole mediastinal LAP olan hastalarda \%44 sarkoidoz, \%36 TB, \%4 lenfoma, \%5 toraks diş1 kanser, \%5 akciğer kanseri, \%5 reaktif lenfadenopati görülmüştür ${ }^{5}$. Ülkemizde yapılan bir çalışmada, mediastinal LAP olan 107 hastaya mediastinoskopi yapılmış ve \%23.5'inde reaktif lenf nodu, \%21.4'ünde sarkoidoz, \%15’inde tüberküloz, \%0.9'unda benign epitelyal kist, \%39.2'sinde malignite saptanmıştır ${ }^{6}$.

Çalışmamızda hastaların 47'sinde (\%52.7) granülomatöz lenfadenit saptanmıştır. Granülomatöz mediastinal/hiler lenfadenit, benign patolojiler arasında önemli bir yer tutar ${ }^{3,7}$. Literatürdeki çalışmalarla benzer şekil- de çalışmamızda da granülomatöz lenfadenit olgularımızın çoğunluğunu sarkoidoz (\%91.8) oluşturmaktadır. Diğer nedenler arasında \%4.1 tüberküloz, \%2 silikozis, \%2 nedeni bilinmeyen yer almıştır. Çetinoğlu ve ark. larının çalışmasında sarkoidoz ön tanısıyla EBUS TBİA yapilan 23 olgunun 18'inde granülomatöz lenfadenit saptanmış ve 17'si sarkoidoz, 1'i tüberküloz dışı mikobakteri olarak tanımlanmıştır ${ }^{8}$. Retrospektif olarak granülomatöz lenfadenit saptanan hastaları incelendiğimiz başka bir çalışmamızda hastaların \%71.8'i sarkoidoz, \%3.6'sı tüberküloz ve \%10.9'u nedeni bilinmeyen olarak bulunmuştur ${ }^{9}$.

Çalışmamızda lenf nodu örneklemesi için seçilen ilk invazif işlem 83 hastada EBUS TBİA, 7 hastada mediastinoskopi, 2 hastada Video-asiste torakoskopik cerrahi (VATS) ve 1 hastada torakotomi olmuştur. Mediastinal/hiler LAP tanısında EBUS TBİA duyarl1lığ $\% 95.08$ ve negatif prediktif değeri \% 93.02 olarak bildirilmiştir ${ }^{10}$. EBUS TBİA'nın mediastinoskopi gereksinimini yaklaşık $\% 87$ oranında azalttığı belirtilmiştir $^{11}$. EBUS duyarlığının yüksek olduğunu gösteren çalışmalar yanında Navani ve ark. larının çalışmasında EBUS TBİA'nın negatif prediktif değerinin düşük olduğu bulunmuş ve bu nedenle negatif EBUS TBİA olgularında mediastinoskopi yapılmasının gerektiği belirtilmiştir ${ }^{5}$. Çalışmamızda EBUS TBİA yapılan 19 hastaya ikinci kez tanısal işlem uygulanmış ve ilk biyopsi ile ikinci biyopsi sonucu arasında tutarlilık bulunmuştur.

Mediastinal/ hiler LAP tanısal verimliliğini etkileyen çeşitli faktörler mevcuttur. Bunlardan bazıları bronkoskopistin beceri ve deneyimi, lenf nodunun örneklenmesinin zor olduğu anatomik koşullar, histopatolojik incelemeyi yapan ekibin tecrübesi olabilir. Tüberküloz lenfadenit tanılı hasta sayımızın az olması, tek merkezli bir çalışma olması ve takip sırasında hastalarımızın önemli bir kısmına ulaşılamaması çalışmamızın kısıtlılıklarıdır.

Sonuç olarak mediastinel/hiler LAP'ların büyük oranda EBUS TBİA yöntemiyle örneklenebildiği, mediastinal/hiler LAP'ların etyolojisinde benign patolojilerin önemli yer tuttuğu, granülomatöz lenfadenitler arasında sarkoidozun asıl neden olduğu ve benign lenfadenopatili hastaların takibi sırasında nihai tanının değişebileceği görülmüştür.

\section{Kaynaklar}

1. Kumar A, Dutta R, Kannan U, et al. Evaluation of mediastinal lymph nodes using 18F-FDG PET-CT scan and its histopathologic correlation. Ann Thorac Med 2011; 6: 11-6.

2. Mukhopadhyay S, Gal AA. Granulomatous lung disease: an approach to the differential diagnosis. Arch Pathol Lab Med 2010; 134: 667- 90 .

3. Nazarullah A, Nilson R, Maselli DJ, et al. Incidence and aetiologies of pulmonary granulomatous inflammation: A decade of experience. Respirology 2015; 20, 115-21. 


\section{Benign Mediastinal/Hiler Lenfadenopatiler}

4. Masi AT, Hunder GG, Lie JT, et al. The American College of Rheumatology 1990 criteria for the classification of ChurgStrauss Syndrome. Arth Rheum 1993; 33: 1094-100.

5. Navani N, Lawrence DR, Kolvekar S, et al. Endobronchia ultrasound-guided transbronchial needle aspiration prevents mediastinoscopies in the diagnosis of isolated mediastinal lymphadenopathy: a prospective trial. Am J Crit Care 2012; 186: 255-60.

6. Oğuz Kapicibaşi H. The role of mediastinoscopy in the diagnosis of thoracic disease: 107-case analysis. Med Glas (Zenica) 2019;16(2).

7. Gürün Kaya A, Çiledag A, Çiftçi F, et al. The underlying causes of granulomatous lymphadenitis detected by EBUSTBNA. European Respiratory Journal 2015; 46: 788.
8. Çetinoğlu Demirdögen E, Ursavaş A, Güçlü Aydın Ö, ark. Sarkoidoz Şüphesi Olan Olgularda EBUS-TBİA Tanı Değeri: Retrospektif Olgu Serisi. Uludağ Üniversitesi Tıp Fakültesi Dergisi 2017; 43(3):109-115.

9. Erbay M, Özsu S, Ayaydın Mürtezaoğlu ES, et al. Causes of mediastinal/hilar granulomatous lymphadenitis. Tuberk Toraks 2018; 66(3):212-216.

10. Ye T, Hu H, Luo X, et al. The role of Endobronchial ultrasound guided transbronchial needle aspiration (EBUS-TBNA) for qualitative diagnosis of mediastinal and hilar lymphadenopathy: a prospective analysis. BMC Cancer 2011; 11-100.

11. Judson MA. Sarcoidosis: clinical presentation, diagnosis and approach to treatment. Am J Med Sci 2008; 335: 26-33. 
